\title{
DIAGNÓSTICOS DE ENFERMAGEM MAIS FREQÜENTES ENTRE IDOSAS HOSPITALIZADAS EM UNIDADE DE CLÍNICA MÉDICA E CIRÚRGICA
}

\author{
MOST COMMON NURSING DIAGNOSES AMONG ELDERLY WOMEN \\ HOSPITALIZED IN CLINICAL AND SURGICAL UNITS \\ DIAGNÓSTICOS DE ENFERMERÍA MÁS FRECUENTES ENTRE \\ ANCIANAS INTERNADAS EN LA UNIDAD DE CLININICA MÉDICAY \\ QUIRÚRGICA
}

\author{
Maria José Sanches Marin ${ }^{\uparrow}$ \\ Pedro Marco Karan Barbosa ${ }^{2}$ \\ Mariko Tanaka Takitane ${ }^{3}$
}

\begin{abstract}
RESUMO:Diante da alta incidência de idosos que se encontram hospitalizados atualmente e as inúmeras necessidades apresentadas por eles, o presente estudo tem como objetivo descrever os diagnósticos de enfermagem mais comuns entre 50 idosas hospitalizadas, as quais foram avaliadas considerando-se ser necessária a continuidade dos cuidados no domicilio. Os autores concluiram que as idosas apresentam diagnósticos em todos os padrōes de resposta humana, com destaque para o déficit de conhecimento.
\end{abstract}

PALAVRAS-CHAVE: diagnóstico de enfermagem, saúde do idoso, hospitalização

\section{INTRODUÇÄO}

O crescente aumento da população idosa que vem ocorrendo nos últimos tempos exige o estabelecimento de novas estratégias para melhor atendê-la. Essa assistência ao idoso deve prezar a manutenção da qualidade de vida, considerando os processos de perdas próprias do envelhecimento e as possibilidades de prevenção, manutençăo e reabilitação do estado de saúde.

A vulnerabilidade dos idosos, tanto do ponto de vista biológico, como social, econômico e espiritual, torna-os mais susceptiveis às doenças e a hospitalização como consequeência.

De acordo com Gutierrez Gambaro (1987), a assistência ao idoso deve ser feita preferencialmente no domicilio, entretanto, se ele for hospitalizado, o hospital deve prepará-lo o mais breve possivel para que possa retornar ao lar em condiçōes fisicas, psiquicas e sociais de independência.

Essa preocupação parece justificar-se pelos inúmeros riscos advindos da hospitalização. Ainda que, entre eles, o mais citado se refira à infecção hospitalar, para o idoso importa

'Doutora em Enfermagem e Docente da Disciplina de Enfermagem em Saúde Coletiva do Curso de Enfermagem da Faculdade de Medicina de Marilia.

${ }^{2}$ Doutorando do Programa de Pós- graduação em Enfermagem Fundamental da EERP- USP e Docente da Disciplina de Enfermagem Clinica do Curso de Enfermagem da Faculdade de Medicina de Marilia.

${ }^{3}$ Mestranda do Programa de Pós- graduação em Enfermagem Fundamental da EERP- USP e Docente da Disciplina de Enfermagem Clínica do Curso de Enfermagem da Faculdade de Medicina de Marilia. 
sobremaneira o confinamento no leito devido aos procedimentos realizados e à falta de estimulo para atividades fisicas e mentais, a dificuldade de adaptar-se a novos ambientes, principalmente, pelas alterações de visão e audição a que se acrescenta o estresse imposto pela doença e pelos procedimentos.

A assistência ao idoso hospitalizado deve visar o preparo do idoso e/ou familiares para a continuidade da assistência no domicilio preparo esse a iniciar-se no momento da internação, quando uma coleta abrangente de dados, sobre o idoso como um todo, ou seja, sobre aspectos biológicos, psicológicos, sociais, econômicos, ambientais e espirituais, norteará as ações da equipe de enfermagem e demais profissionais envolvidos na assistência.

Com a finalidade de verificar as reais necessidades dessa parcela da população e preparar o idoso e/ou seus familiares para continuidade da assistência no domicilio, foi implementada a sistematização da assistência de enfermagem a 50 idosas, as quais foram acompanhadas durante todo o processo de hospitalização, ocasião em que se estabeceram os diagnósticos de enfermagem segundo a Taxionomia da NANDA ( North American Nursing Diagnosis Association).

Segundo Farias et al. (1990, p. 26), o diagnóstico de enfermagem foi definido na $9^{\text {a }}$ Conferência da NANDA como "Um julgamento clínico das respostas do indivíduo, da familia ou da comunidade aos processos vitais ou aos problemas de saúde atuais ou potenciais, os quais fornecem a base para a seleção das intervenções de enfermagem, para atingir resultados pelos quais o enfermeiro é responsável".

Os diagnósticos de enfermagem obedecem a um método útil para organização do conhecimento de enfermagem, dado que um dos requisitos para uma ocupação alcançar o status de profissão é possuir um corpo de conhecimentos próprio e desenvolver açōes com autonomia e autodeterminação (Carpenito, 1997).

Ainda que existam várias propostas de uniformização da terminologia usada pelos enfermeiros ao se referirem ao mesmo problema de saúde do cliente, a que vem ganhando maior destaque é a apresentada pela NANDA, grupo de estudo preocupado com o assunto, desde a década de 70, atualmente publicada como Taxionomia I Revisada. Esta propõe nove padrōes que, quando em equilibrio, manifestam a saúde: trocar, comunicar, valorizar, escolher, relacionar, mover, perceber, conhecer e sentir (Nóbrega e Garcia, 1994).

O presente estudo propõe-se a descrever os diagnósticos de enfermagem mais comuns, de acordo com os 9 padrões de resposta humana proposto pela NANDA, encontrados nas 50 idosas. A sistematização dessa assistência de enfermagem foi implementada visando ao preparo das idosas e/ou familiares para continuidade da assitência no domicilio.

Na determinação dos diagnósticos de enfermagem, considerou-se a definição diagnóstica, as caracteristicas definidoras e os fatores relacionados, conforme a taxionomia revisada da NANDA, porém com adaptações feitas para a nossa realidade por Nóbrega e Garcia (1994).

\section{METODOLOGIA}

LOCAL

O presente estudo foi realizado na Unidade de Clínica Médica e Cirúrgica Feminina do Hospital das Clínicas I da Faculdade de Medicina de Marilia, a qual conta com 18 leitos e foi escolhida por tratar-se do local de atuação de uma das autoras e caracterizar-se pelo atendimento de grande quantidade de idosas.

\section{A POPULAÇÃO DO ESTUDO}

O estudo contou com a participação de 50 idosas (acima de 60 anos) que se encontravam 
internadas na unidade referida acima e que residiam em Marilia, as quais não se apresentavam em estado grave, com forte ameaça à vida, sendo possivel a implementação da sistematização da assistência visando o preparo da idosa e/ou cuidador para a continuidade da assistência no domicilio. Quando a idosa apresentava algum grau de dependência, solicitou-se a presença de um acompanhante para participar do processo de assistência

\section{O PROCEDIMENTO DA COLETA DE DADOS}

Para implementação do estudo foram necessárias algumas modificações na organização da unidade, uma vez que a mesma não contava com a sistematizaçăo da assistência de enfermagem. Para tanto, levou-se em consideração a disponibilidade de recursos humanos, materiais e de área fisica da instituição. Tais modificaçōes compreenderam elaboração do manual de cuidados de enfermagem ao idoso hospitalizado, treinamento do pessoal que presta assistência, promoçăo do envolvimento dos demais membros da equipe multiprofissional, criação de instrumento de registro das informações colhidas e das atividades desenvolvidas (coleta de dados, diagnóstico de enfermagem e plano de ação).

Para a coleta de dados, foi elaborado um instrumento, de acordo com a teoria das necessidades Humanas Básicas de Maslow (1970), a qual permite obter informaçōes a respeito do idoso em sua totalidade, incluindo a dinâmica ambiental e as relações familiares e comunitária, o que possibilitou estabelecer os diagnósticos e determinar as açōes de enfermagem.

Após esse momento, o processo diagnóstico foi realizado segundo o proposto por Helland (1995), através da análise (categorização dos dados e identificação das lacunas) e sintese (agrupamentos dos dados relacionados em padrões); aplicação de modelos, normas, conceitos, teorias e padrões apropriados e comparados com os padrões do cliente; a identificação de respostas humanas incluindo suas capacidades e problemas de saúde e a identificação de fatores que contribuem para as respostas do cliente.

Para discussăo do diagnóstico de enfermagem, considerou-se o proposto pela NANDA (1996,p.90) que compreende: título - dá o nome ao diagnóstico; fatores relacionados "...condiçōes ou circunstâncias que contribuem para o desenvolvimento do diagnóstico de enfermagem" e características definidoras - "... indicadores ou referências observáveis que se agrupam como manifestações de um diagnóstico".

\section{ASPECTOSÉTICOS}

Para efetivar a coleta de dados foi solicitada autorizaçăo à comissão de ética da Faculdade de Medicina de Marilia, a qual se manifestou favorável à mesma.

Antes de iniciar a coleta de dados, as idosas e/ou cuidadores foram orientados quanto à finalidade do estudo, ao procedimento e informados de que estariam livres para participar ou não da pesquisa. Quando houve interesse em participar, solicitou-se a pessoa para assinar o termo de consentimento.

\section{RESULTADO E DISCUSSÄO}

\section{CARACTERIZAÇÃO GERAL DAS IDOSAS}

Entre as idosas em estudo, 22 (44\%) são pertencentes à faixa etária de 60 a 69 anos, 17 ( $32 \%$ ) entre 70 e 79 anos, sete $(20 \%)$ entre 80 e 89 anos, sendo que apenas quatro ( $8 \%$ ) delas tinham 90 anos ou mais. Quanto ao grau de comunicação, $35(70 \%)$ das idosas apresentavamse em boas condições de comunicação verbal, enquanto cinco delas $(10 \%)$ eram pouco comunicativas, cinco (10\%) eram confusas e outras cinco $(10 \%)$ eram afásicas. Das idosas 
Diagnósticos de Enfermagem...

estudadas 31 (62\%) eram analfabetas, três (6\%) tinham o ensino fundamental completo e as demais eram alfabetizadas.

O periodo de internação variou entre um a cinco dias para seis (12\%) das idosas, de seis a dez dias para $22(44 \%)$ delas e para as demais por um tempo mais longo, sendo que quatro $(8 \%)$ delas permaneceram por mais de 30 dias no hospital.

As doenças mais incidentes entre elas referem-se àquelas do sistema cardiocirculatório, seguindo-se as doenças das glândulas endócrinas, nutrição e metabolismo, as do sistema respiratório e as do sistema osteoarticular e tecido conjuntivo, entre outras. Referindo-se aos medicamentos, as 50 idosas do estudo faziam uso em média de 2,6 medicamentos / idosa.

Das idosas em estudo 42 (84\%) apresentavam algum grau de dependência, o que demandou a presença de um cuidador para sua assistência. Esses e outros dados foram utilizados, então, para a elaboração dos diagnósticos de enfermagem, conforme seguem.

\section{OS DIAGNÓSTICOS DE ENFERMAGEM ENCONTRADOS ENTRE AS IDOSAS}

\section{QUADRO 1 - DISTRIBUIÇÃO DOS DIAGNÓSTICOS DE ENFERMAGEM, OS RESPECTIVOS FATORES RELACIONADOS E CARACTERISTICAS DEFINIDORAS DO PA- DRÃO DE RESPOSTA HUMANA: TROCAR continua}

\begin{tabular}{|c|c|c|}
\hline Diagnóstico & Fatores relacionados/Fatores de risco & $\begin{array}{l}\text { Caracteristicas } \\
\text { definidoras }\end{array}$ \\
\hline $\begin{array}{l}\text { Nutrição } \\
\text { alterada: } \\
\text { ingestão } \\
\text { menor do que } \\
\text { as } \\
\text { necessidades } \\
\text { corporais }\end{array}$ & $\begin{array}{l}\text { Inabilidade para ingerir ou digerir alimentos ou } \\
\text { absorver nutrientes, devido a fatores biológicos, } \\
\text { psicológicos, econômicos e culturais, falta ou } \\
\text { déficit de informação sobre alimentação } \\
\text { adequada, conceitos errados sobre prática } \\
\text { alimentar. }\end{array}$ & $\begin{array}{l}\text { Perda de peso, fraqueza } \\
\text { dos músculos usados na } \\
\text { mastigação e na } \\
\text { deglutição, falta de } \\
\text { alimento, alteração na } \\
\text { sensação gustativa, falta } \\
\text { de interesse por } \\
\text { alimentar-se, conjuntiva e } \\
\text { mucosas pálidas, tônus } \\
\text { muscular enfraquecido. }\end{array}$ \\
\hline $\begin{array}{l}\text { Risco para } \\
\text { infecção }\end{array}$ & $\begin{array}{l}\text { Defesa primária insuficiente, defesa secundária } \\
\text { insuficiente, doença crônica, procedimentos } \\
\text { invasivos, desnutrição. }\end{array}$ & $\begin{array}{l}\text { Idem fatores } \\
\text { relacionados }\end{array}$ \\
\hline $\begin{array}{l}\text { Constipação } \\
\text { colônica }\end{array}$ & $\begin{array}{l}\text { Ingestão de líquidos menor do que a adequada, } \\
\text { ingestão de alimentos menor do que a } \\
\text { adequada, atividade fisica menor que a } \\
\text { adequada, imobilidade, uso crônico de } \\
\text { medicamentos e enemas, }\end{array}$ & $\begin{array}{l}\text { Freqüência reduzida, } \\
\text { fezes secas e } \\
\text { endurecidas, esforço para } \\
\text { evacuar, evacuação } \\
\text { dolorosa, distensão } \\
\text { abdominal, massa } \\
\text { palpável, dor abdominal. }\end{array}$ \\
\hline $\begin{array}{l}\text { Eliminação } \\
\text { urinária } \\
\text { alterada }\end{array}$ & Causas múltiplas & $\begin{array}{l}\text { Disúria, freqüência de } \\
\text { eliminação urinária } \\
\text { aumentada ou diminuída, } \\
\text { tenesmo miccional, } \\
\text { incontinência, nictúria, } \\
\text { retenção urinária, } \\
\text { sensação de urgência } \\
\text { para urinar. }\end{array}$ \\
\hline $\begin{array}{l}\text { Risco para } \\
\text { trauma }\end{array}$ & $\begin{array}{l}\text { Fatores internos: fraqueza, diminuição da } \\
\text { acuidade visual, dificuldade de equilibrio, } \\
\text { redução grande ou pequena da coordenação, } \\
\text { falta de educação em ass untos de segurança } \\
\text { ambiental e história de trauma anterior. Fatores } \\
\text { de risco externos: pisos escorregadios, tapetes } \\
\text { soltos, escadas sem segurança e iluminação } \\
\text { insuficiente. }\end{array}$ & $\begin{array}{l}\text { Idem aos fatores de } \\
\text { relacionados }\end{array}$ \\
\hline
\end{tabular}


QUADRO 1 - DISTRIBUIÇÃO DOSDIAGNÓSTICOS DE ENFERMAGEM, OS RESPECTIVOS FATORES RELACIONADOS E CARACTERISTICAS DEFINIDORAS DO PADRÃO DE RESPOSTA HUMANA: TROCAR conclusão

\begin{tabular}{|c|c|c|}
\hline $\begin{array}{l}\text { Risco para } \\
\text { aspiração }\end{array}$ & $\begin{array}{l}\text { Diminuição do nivel de consciência, depressão } \\
\text { dos reflexos de tosse e deglutição, presença de } \\
\text { traqueostomia e sonda nasogástrica }\end{array}$ & $\begin{array}{l}\text { Idem aos fatores } \\
\text { relacionados }\end{array}$ \\
\hline $\begin{array}{l}\text { Risco para } \\
\text { déficit no } \\
\text { volume de } \\
\text { liquido }\end{array}$ & $\begin{array}{l}\text { Extremos de idade, extremos de peso, } \\
\text { excessivas perdas de líquido por vias normais, } \\
\text { alterações que afetam o acesso, a ingestão ou } \\
\text { a absorção de líquidos, deficiência de } \\
\text { conhecimentos relacionados com as } \\
\text { necessidades de volume de liquidos, uso de } \\
\text { diuréticos. }\end{array}$ & $\begin{array}{l}\text { Idem aos fatores } \\
\text { relacionados }\end{array}$ \\
\hline $\begin{array}{l}\text { Integridade } \\
\text { tissular } \\
\text { prejudicada }\end{array}$ & $\begin{array}{l}\text { Circulação alterada, déficit ou excesso } \\
\text { nutricional, mobilidade física prejudicada }\end{array}$ & \\
\hline $\begin{array}{l}\text { Risco para } \\
\text { síndrome do } \\
\text { desuso }\end{array}$ & $\begin{array}{l}\text { Imobilidade, dor, alteração do nível da } \\
\text { consciência. }\end{array}$ & $\begin{array}{l}\text { Idem aos fatores } \\
\text { relacionados }\end{array}$ \\
\hline $\begin{array}{l}\text { Risco para } \\
\text { integridade da } \\
\text { pele } \\
\text { prejudicada }\end{array}$ & $\begin{array}{l}\text { Fatores mecânicos, imobilização física, } \\
\text { umidade, alteração no estado nutricional, } \\
\text { alteração circulatória, proeminência óssea, } \\
\text { alteração do turgor e na elasticidade. }\end{array}$ & $\begin{array}{l}\text { Idem aos fatores } \\
\text { relacionados }\end{array}$ \\
\hline
\end{tabular}

As idosas em estudo apresentam tanto diagnósticos atuais (processo já existentes no individuo) como potenciais (existência de risco).

Referindo-se ao padrão de resposta humana trocar, os diagnósticos mais freqüentes entre as 50 idosas encontram-se descritos no quadro 1. Entre eles, nutrição alterada, risco para infecção, constipação colônica, eliminação urinária alterada, risco para trauma, potencial para déficit no volume de líquido, integridade tissular prejudicada, risco para síndrome de desuso e risco para integridade da pele prejudicada.

Ao observarmos os fatores relacionados e as características definidoras constantes no quadro 1, relativas ao padrão TROCAR, constata-se na maioria das vezes, que são condições do próprio processo de envelhecimento em que as alterações fisiológicas tornam o organismo vulnerável a múltiplas perdas e suas conseqüências.

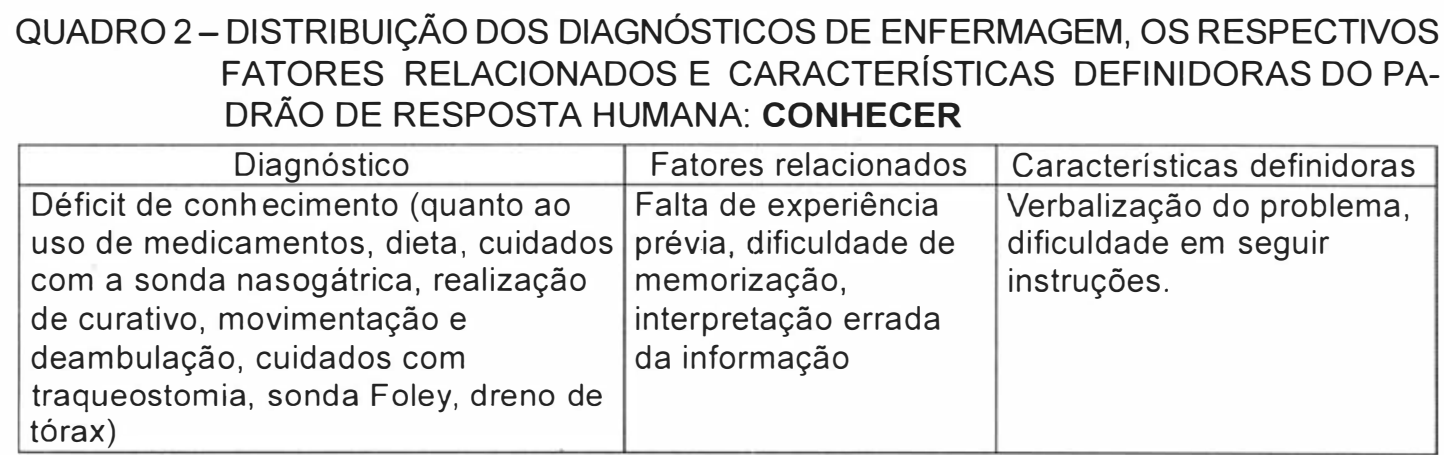

Percebeu-se que para o proposto no estudo, a descrição dos diagnósticos mais comuns ao se implementar a sistematização da assistência de enfermagem a um grupo de idosas, com a finalidade de prepara-las para a continuidade da assistência no domicilio, além da assistência direta no hospital, o diagnóstico de déficit de conhecimento foi bastante freqüente, uma vez que tanto as idosas como os seus cuidadores desconheciam a doença, uso de medicamentos, atividade física e diversos procedimentos a que as idosas teriam de submeter-se.

Os fatores relacionados, ou seja, os determinantes do diagnóstico de enfermagem, referemse à falta de experiência, dificuldade de memorização e até mesmo interpretação errada da 
Diagnósticos de Enfermagem...

informação. Tais fatores são freqüentes nos idosos devido às alterações próprias do processo de envelhecimento, entre elas o déficit visual e auditivo e a própria dificuldade de memorização (Graves, 1988).

QUADRO 3 -DISTRIBUIÇÃO DOS DIAGNÓSTICOS DE ENFERMAGEM, OS RESPECTIVOS FATORES RELACIONADOS E CARACTERISTICAS DEFINIDORAS DO PADRÃO DE RESPOSTA HUMANA: COMUNICAR

\begin{tabular}{|l|l|l|}
\hline \multicolumn{1}{|c|}{ Diagnóstico } & \multicolumn{1}{|c|}{ Fatores relacionados } & \multicolumn{1}{c|}{ Características definidoras } \\
\hline $\begin{array}{l}\text { Comunicação } \\
\text { prejudicada }\end{array}$ & $\begin{array}{l}\text { Percepção alterada, alterações } \\
\text { do sistema nervoso central, } \\
\text { enfraquecimento musculo- } \\
\text { esquelético. }\end{array}$ & $\begin{array}{l}\text { Desorientação auto e alopsíquica, } \\
\text { dificuldade de verbalizar ou falar, } \\
\text { expressar por afonia ou disfonia, déficit } \\
\text { auditivo total ou parcial, déficit visual } \\
\text { parcial ou total. }\end{array}$ \\
\hline
\end{tabular}

No quadro 3, que aponta para o padrão de resposta humana COMUNICAR, constatou-se entre as 50 idosas, o diagnóstico de comunicação prejudicada. Essa alteração costuma ser freqüente, apresentando várias causas, conforme as apresentadas nos fatores relacionados, e interferem sobremaneira na sua qualidade de vida uma vez que isso os impede de manifestar suas necessidades e assim merecem estratégias de assistência adequadas para amenizar o sofrimento dessas pessoas (Parker,1998)

\section{QUADRO 4 - DISTRIBUIÇÃO DOS DIAGNÓSTICOS DE ENFERMAGEM, OS RESPECTIVOS FATORES RELACIONADOS E CARACTERISTICAS DEFINIDORAS DO PA- DRÄO DE RESPOSTA HUMANA: VALORIZAR}

\begin{tabular}{|l|l|l|}
\hline Diagnóstico & \multicolumn{1}{|c|}{$\begin{array}{c}\text { Fatores } \\
\text { relacionados }\end{array}$} & \multicolumn{1}{c|}{ Caracteristicas definidoras } \\
\hline $\begin{array}{l}\text { Angústia } \\
\text { espiritual }\end{array}$ & $\begin{array}{l}\text { Separação de laços } \\
\text { religiosos ou } \\
\text { culturais }\end{array}$ & $\begin{array}{l}\text { Preocupação expressa com o significado da vida ou da } \\
\text { morte elou com sistema de crenças, questionamento do } \\
\text { significado do sofrimento, incapacidade para participar } \\
\text { de práticas religiosas usuais, busca de assistência } \\
\text { espiritual. }\end{array}$ \\
\hline
\end{tabular}

Quanto ao diagnóstico de Angustia Espiritual, incluido no padrão de resposta humana VALORIZAR, e identificado entre as idosas do estudo (quadro 4), parece relacionado não só ao afastamento de laços religiosos ou culturais, conforme descrito pela NANDA, mas também, à sensação de proximidade da morte e medo da doença, muito comuns nessas pessoas. A religião, freqüentemente, proporciona conforto e refúgio para as angústias típicas da terceira idade, eqüivalendo, assim, a um suporte psicológico.

QUADRO 5-DISTRIBUIÇÃO DOS DIAGNÓSTICOS DE ENFERMAGEM, OS RESPECTIVOS FATORES RELACIONADOS E CARACTERISTICAS DEFINIDORAS DO PADRÄO DE RESPOSTA HUMANA: ESCOLHER continua

\begin{tabular}{|l|l|l|}
\hline Diagnóstico & \multicolumn{1}{|c|}{ Fatores relacionados } & \multicolumn{1}{c|}{ Características definidoras } \\
\hline $\begin{array}{l}\text { Adaptação } \\
\text { prejudicada }\end{array}$ & $\begin{array}{l}\text { Sistemas de suporte } \\
\text { inadequados, déficit de } \\
\text { conhecimento, sobrecarga } \\
\text { sensorial, agressão à auto - } \\
\text { estima, conflito não } \\
\text { resolvido }\end{array}$ & $\begin{array}{l}\text { Verbalização de não aceitaça da mudana } \\
\text { no estado de saúde, inabilidade e habilidade } \\
\text { mal sucedida para envolver-se na solução de } \\
\text { problemas ou fixação de metas, inabilidade } \\
\text { para efetuar mudanças no estilo de vida, falta } \\
\text { de empenho para tornar-se independente, } \\
\text { periodo prolongado de raiva, relacionado a } \\
\text { mudança no estado de saúde, ausência de } \\
\text { planos para o futuro. }\end{array}$ \\
\hline
\end{tabular}


QUADRO 5-DISTRIBUIÇÃO DOS DIAGNÓSTICOS DE ENFERMAGEM, OS RESPECTIVOS FATORES RELACIONADOS E CARACTERISTICAS DEFINIDORAS DO PADRĀO DE RESPOSTA HUMANA: ESCOLHER

conclusão

\begin{tabular}{|c|c|c|}
\hline $\begin{array}{l}\text { Estratégias } \\
\text { ineficazes de } \\
\text { resolução } \\
\text { familiar: } \\
\text { incapacitantes } \\
\text { e compromete- } \\
\text { doras }\end{array}$ & $\begin{array}{l}\text { Pessoas significativas com } \\
\text { sentimentos de hostilidade, } \\
\text { ansiedade e desespero, } \\
\text { desorganização familiar e } \\
\text { mudança de papéis, } \\
\text { doença prolongada e } \\
\text { incapacidade progressiva } \\
\text { que esgota a capacidade } \\
\text { de apoio das pessoas }\end{array}$ & $\begin{array}{l}\text { Negligência no atendimento as necessidades } \\
\text { humanas básicas do cliente e no tratamento } \\
\text { da doença, intolerância, rejeiçäo, hostilidade, } \\
\text { queixa do paciente sobre a resposta de } \\
\text { pessoas significativa ao seu problema de } \\
\text { saúde, pessoas significativas demonstrando } \\
\text { comportamento protetor, ignorando a } \\
\text { habilidade e necessidade de autonomia do } \\
\text { cliente. }\end{array}$ \\
\hline
\end{tabular}

No padrăo de resposta humana ESCOLHER, os diagnósticos apresentados pelas 50 idosas foram a Adaptação Prejudicada e Estratégias Ineficazes de Resolução Familiar tanto incapacitantes como comprometedoras (quadro 5).

O contexto familiar, incluindo seus recursos, relaçōes, habilidade e conhecimentos para cuidar do idoso, deve ser considerado ao planejar a assistência de enfermagem para idosos, principalmente quando apresentam alguma dependência, uma vez que dele depende grande parte do seu bem estar, conforme descrito nos fatores relacionados e caracteristicas definidoras.

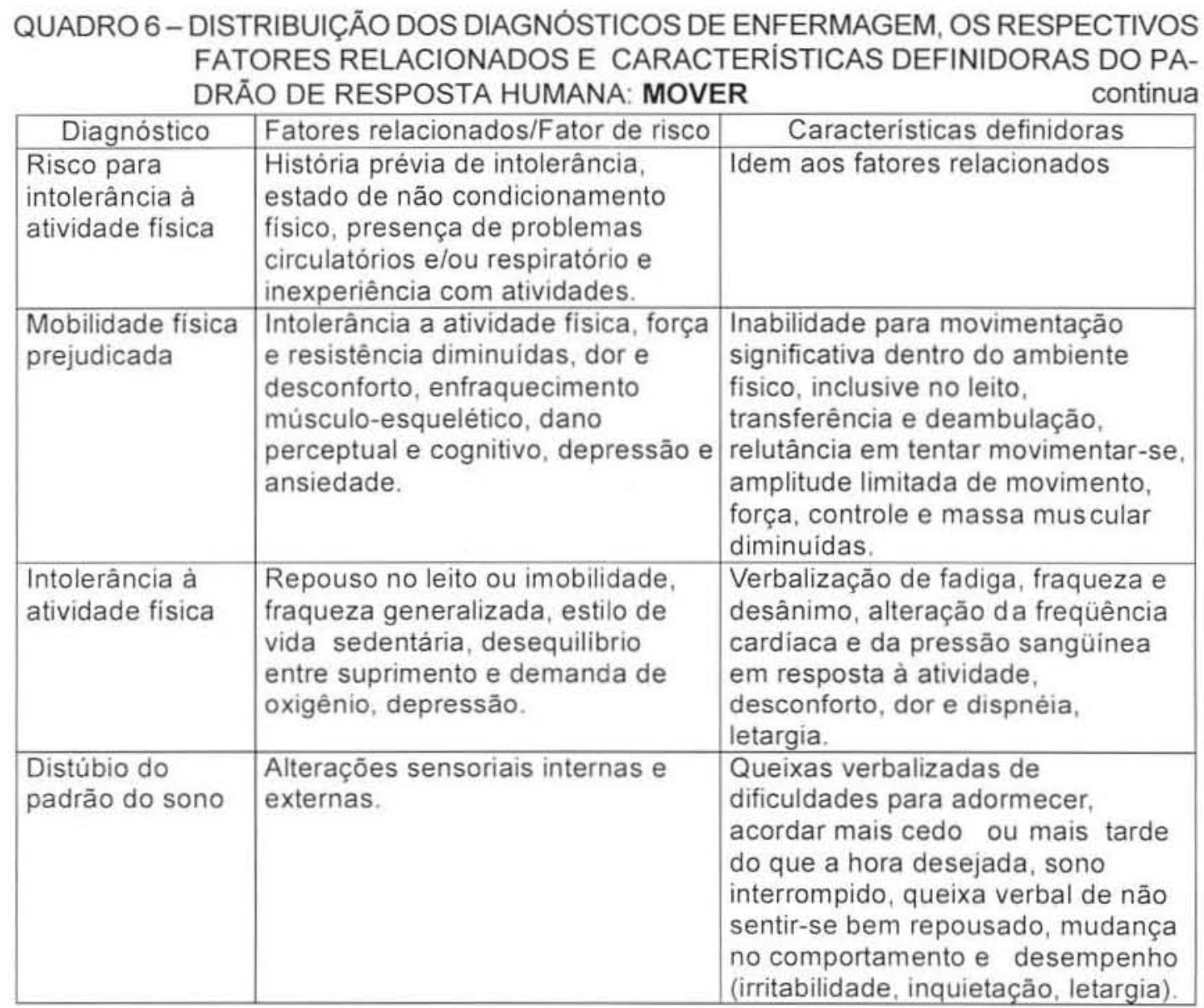




\begin{tabular}{|c|c|c|}
\hline $\begin{array}{l}\text { Manutenção do } \\
\text { lar prejudicada }\end{array}$ & $\begin{array}{l}\text { Organização do lar insuficiente, } \\
\text { finanças insuficientes, função } \\
\text { emocional e cognitiva prejudicada, } \\
\text { falta de conhecimento, sistemas de } \\
\text { apoio inadequados. }\end{array}$ & $\begin{array}{l}\text { Dificuldade expressa por membro } \\
\text { da familia em manter o lar num } \\
\text { padrāo confortảvel, necessidade } \\
\text { de assistência para manutenção da } \\
\text { moradia, débitos significativos ou } \\
\text { crise financeira relatados por } \\
\text { membros da familia. }\end{array}$ \\
\hline \begin{tabular}{|l|} 
Déficit de \\
autocuidado: \\
alimentaçâo, \\
higiene corporal, \\
verstir-se e/ou \\
arrumar-se, \\
higiene intima \\
\end{tabular} & $\begin{array}{l}\text { Intolerância à atividade fisica, força } \\
\text { e resistência diminuidas, dor e } \\
\text { desconforto, dificuldade perceptual } \\
\text { e cognitiva, enfraquecimento } \\
\text { neuromuscular, enfraquecimento } \\
\text { músculo-esquelético, depressão ou } \\
\text { ansiedade severa. }\end{array}$ & $\begin{array}{l}\text { Inabilidade para trazer o alimento } \\
\text { até a boca, inabilidade para lavar o } \\
\text { corpo ou parte do corpo, para } \\
\text { vestir-se e retirar as roupas, para } \\
\text { manter aparência a um nivel } \\
\text { satisfatório, para realizar os } \\
\text { cuidados de higiene intima. }\end{array}$ \\
\hline
\end{tabular}

Os diagnósticos do padrão de resposta humana MOVER, conforme descrito no quadro 6 , indicam as limitações físicas dessas pessoas e consequentemente o seu grau de dependência, o que tem relaçăo muito direta com sua qualidade de vida. A dependência de outros parece estar relacionada com a sensação de incapacidade e esse é o momento, para a maioria das pessoas, "sentir-se realmente velho". Em nossa sociedade, a falta de cultura voltada para o aproveitamento das potencialidades existentes nos idosos, e até de condutas adequadas no sentido de reabilitá-los torna mais dificil essa situação caótica (Datilo, 1998).

\section{QUADRO 7-DISTRIBUIÇÃO DOS DIAGNÓSTICOS DE ENFERMAGEM, OS RESPECTIVOS FATORES RELACIONADOS E CARACTERISTICAS DEFINIDORAS DO PA- DRÄO DE RESPOSTA HUMANA:}

\begin{tabular}{|l|l|l|}
\hline \multicolumn{1}{|c|}{ Diagnóstico } & \multicolumn{1}{|c|}{ Fatores relacionados } & \multicolumn{1}{c|}{ Caracteristicas definidoras } \\
\hline $\begin{array}{l}\text { Interação social } \\
\text { prejudicada }\end{array}$ & $\begin{array}{l}\text { Déficit de conhecimento e de } \\
\text { habilidade para aumentar a } \\
\text { interação, barreiras de } \\
\text { comunicação, ausência de pessoas } \\
\text { significativas ou grupos significativos } \\
\text { disponiveis, limitação de mobilidade } \\
\text { fisica, terapêutica de isolamento, } \\
\text { alteraçōes do processo do } \\
\text { pensamento }\end{array}$ & $\begin{array}{l}\text { Inabilizada ou } \\
\text { observada para receber ou } \\
\text { comunicar uma sensação } \\
\text { gratificante de pertencer, cuidar, } \\
\text { interessar-se ou compartilhar com } \\
\text { outros, disfunção interativa com } \\
\text { seu grupo etário, familia elou } \\
\text { outros. }\end{array}$ \\
\hline
\end{tabular}

Outro diagnóstico comumente encontrado entre as idosas alvo do estudo, refere-se à interaçăo social prejudicada, conforme se discute nos fatores relacionados (quadro 7), podem acontecer devido a alterações físicas, mentais e emocionais como a ausência de pessoas ou grupos significativos. 


\section{QUADRO 8-DISTRIBUIÇÃO DOS DIAGNÓSTICOS DE ENFERMAGEM, OS RESPECTIVOS FATORES RELACIONADOS E CARACTERISTICAS DEFINIDORAS DO PA- DRÄO DE RESPOSTA HUMANA: PERCEBER}

\begin{tabular}{|l|l|l|}
\hline Diagnóstico & Fatores relacionados & \multicolumn{1}{|c|}{ Caracteristicas definidoras } \\
\hline Impotência & $\begin{array}{l}\text { Interação } \\
\text { interpessoal } \\
\text { inadequada, estilo de } \\
\text { vida de desamparo, } \\
\text { doença crônico- } \\
\text { degenerativa. }\end{array}$ & $\begin{array}{l}\text { Expressões verbais relativas à falta de controle ou } \\
\text { de influência sobre uma situação, à falta total de } \\
\text { controle ou de influência sobre um resultado, à falta } \\
\text { total de controle sobre o autocu idado, apatia, } \\
\text { dependência de outros. }\end{array}$ \\
\hline
\end{tabular}

As 50 idosas do estudo expressaram sensações de impotência devido ao desamparo pelas pessoas que lhe são queridas, à presença de múltiplas patologias e limitações diversas que as impedem de viver de forma produtiva e participativa, levando-as ao desânimo. Percebeuse, então, que,, ao referir-se ao padrão de resposta humana PERCEBER, proposto por NANDA, o diagnóstico de impotência foi bastante comum entre as idosas do estudo, conforme descrito no quadro 8.

QUADRO 9 - DISTRIBUIÇÃO DOS DIAGNÓSTICOS DE ENFERMAGEM, OS RESPECTIVOS FATORES RELACIONADOS E CARACTERISTICAS DEFINIDORAS DO PADRÃO DE RESPOSTA HUMANA: SENTIR

\begin{tabular}{|l|l|l|}
\hline Diagnóstico & Fatores relacionados & \multicolumn{1}{|c|}{ Caracteristicas definidoras } \\
\hline Dor & $\begin{array}{l}\text { Agentes de injúria } \\
\text { fisicos e psicológicos }\end{array}$ & $\begin{array}{l}\text { Comportamento defensivo e protetor, comportamento } \\
\text { compativel com desconforto (gemer, chorar, } \\
\text { inquietação), expressão facial de dor, alteração do } \\
\text { tônus muscular. }\end{array}$ \\
\hline $\begin{array}{l}\text { Disfunção na } \\
\text { reação do } \\
\text { pesar }\end{array}$ & $\begin{array}{l}\text { Perda real ou } \\
\text { percebida de objeto } \\
\text { (incluindo pessoas, } \\
\text { bens, trabalho, } \\
\text { status, lar, ideais, } \\
\text { partes e processos } \\
\text { do corpo, entre } \\
\text { outros). }\end{array}$ & $\begin{array}{l}\text { Expressão verbal de angústia diante da perda, } \\
\text { expressão de culpa, expressão de conflito não } \\
\text { resolvidos, tristeza prolongada, choro prolongado, } \\
\text { alteração no hábitos de comer, no padrão d o sono, } \\
\text { no nivel de atividade, recordação de experiências } \\
\text { passadas. }\end{array}$ \\
\hline
\end{tabular}

No padrão de resposta humana SENTIR, os diagnósticos de dor e disfunção na reação do pesar foram os diagnósticos mais freqüentes. A dor causada tanto por agentes fisicos como psicológicos proporciona intenso desconforto para a pessoa, agravando-se devido ao fato desse sintoma ser subestimado nas pessoas idosas ser subestimado, principalmente, quando elas apresentam alterações mentais. Assim sendo, a identificação das caracteristicas definidoras, como expostas no quadro 9 , além de verbalização são fundamentais para sua constatação.

\section{CONSIDERAÇŌES FINAIS}

As idosas do estudo apresentam diagnóstico de enfermagem nos nove padröes de resposta humana proposto pela NANDA (trocar, conhecer, comunicar, perceber, mover, relacionar, sentir, escolher e valorizar), o que ressalta a necessidade de visualizar o idoso como um todo 
para que a assistência de enfermagem atente à multiplicidade de fatores que afetam o seu estado de saúde

Dentre os diagnósticos discutidos, o mais freqüente e importante foi "déficit de conhecimento, pelo próprio objetivo a que se propunha a assistência de enfermagem a ser desenvolvida na ocasião da elaboração dos diagnósticos, a qual previa o preparo do idoso da familia para a alta hospitalar.

Ressalta-se, nesse caso, que a estratégia de assistência a ser empregada refere-se ao processo de ensino- aprendizagem, estratégia essa que deve ser utilizada pelos enfermeiros que atuam na área assistencial de forma contínua. Ao utilizar-se da estratégia de ensino aprendizagem, o enfermeiro desenvolve conhecimentos a respeito da doença, dos medicamentos e procedimentos a serem realizados, além da habilidade manual. Claro está, portanto, que o idoso e/ou cuidador devem participar do desenvolvimento da assistência prestada nesse momento e adquirir os conhecimentos necessários para a continuidade da assistência no domicilio. A partir dessas considerações, o preparo para alta hospitalar deve iniciar-se desde a internação, momento em que se realiza a coleta de dados, contemplando os múltiplos aspectos que envolvem a saúde do paciente, o que possibilitará a compreensão dos fatores que estariam interferindo no seu bem estar, no domicilio, além de se familiarizar com os cuidados a serem prestados.

Com a elaboração do diagnóstico de enfermagem segundo NANDA, ao nosso ver, a visualização do idoso como um todo, bem como a interrelação dos fatores que são causas e efeitos de uma dada situação facilitam a elaboração de estratégias a serem implementadas na assistência de enfermagem

ABSTRACT:Due to the high incidence of elderly people which are presently hospitalized and the countless needs presented by them, this study aimed at describing the most common nursing diagnoses among fifty elderly hospitalized women, who were evaluated considering their need for home care. The authors concluded that the subjects studied presented diagnoses which involved all types of human response patterns, with particular emphasis on the diagnosis of knowledge deficit.

KEYWORDS: nursing diagnoses, health of elderly women, hospitalization

RESUMEN: Ante la alta incidencia de ancianos que están hospitalizados actualmente y las innumerables necesidades que ellos presentan este estudio tiene como objeto describir los diagnósticos de enfermeria más comunes entre 50 ancianas hospitalizadas, quienes fueron evaluadas considerándose las necesidades de continuidad de los cuidados en el domicilio. Los autores concluyeron que las ancianas presentaban diagnósticos en todos los patrones de respuesta humana, dentro de los cuales sobresale el diagnóstico de déficit de conocimiento.

PALABRAS CLAVE: diagnóstico de enfermeria, salud del anciano, hospitalización

\section{REFERÊNCIAS BIBLIOGRÁFICA}

CARPENITO, L. J. Diagnóstico de enfermagem: aplicação à prática clinica. 6. ed. Porto Alegre: Artes Médicas, 1997. 812 p.

DÁTILO, G. M. P. A. O envelhecimento: encantos e desencantos a partir de depoimentos de pessoas com mais de sessenta anos. 1998. 186 p. Dissertação (Mestrado em Educação) - Faculdade de Filosofia e Ciências, Universidade Estadual Paulista, Campus de Marilia. 
FARIAS, J. N. et al. Diagnóstico de enfermagem: uma abordagem conceitual e prática. Joāo Pessoa: Santa Marta, 1990. 160 p.

GRAVES, M. Physiologic changes. In: Nursing care of older adult. 2nd ed. Albany: Delmar, 1988 , cap. 3, p. $83-90$.

GUTIERREZ GAMBARO, A. Atención y cuidado de enfermeria en el paciente senescente. Revista de la Sanidad de la Defensa Nacional (Santiago de Chile), v.4, n.4, p. 366-371, 1987.

HELLAND, W. Y. Nursing diagnosis: diagnostic process. In: CHRISTENSEN, P. J., KENNEY J. W. Nursing process: application of conceptual models. 4th ed. St. Louis: Mosby, 1995. Cap. 7, p. 120-138.

MASLOW, A. H. Motivation and personality. 2nded. New York: Harper \& Row, 1970. 305 p.

NÓBREGA, M. L.; GARCIA, T. R. (Orgs). Uniformizaçäo da linguagem dos diagnósticos da NANDA: sistematizaçāo das propostas do II SNDE. Joảo Pessoa: Uniāo, CNRDE/GIDE, 1994. 138 p.

NANDA - NORTH AMERICAN NURSING DIAGNOSIS ASSOCIATION. Nursing diagnosis: definitions and classification , 1997 - 1998. Philadelphia, 1996. 113 p.

PARKER, B. Realizing the presense of pain in cognitive impaired older adults. Journal of Gerontological Nursing. v.24, n.6, p. 21-28, 1998.

Recebido em março de 2000

Aprovado em junho de 2001 